\title{
A política de habitação de interesse social e a dimensão urbana em municípios da Amazônia/ Pará
}

\author{
Rovaine Ribeiro ${ }^{1}$
}

1 Doutora em Geografia. Professora da Universidade Federal do Pará, Brasil. E-mail: rovainehagn@gmail.com

RESUM 0: 0 presente texto trata da relação entre a política urbana de habitação de interesse social no Brasil em seu período recente e a diversidade urbano-regional da Amazônia e em particular em alguns municípios do Pará. Nesse sentido, apontamos como questões centrais: a) A relação entre a política urbana de habitação de interesse social no Brasil e a diversidade urbano-regional dos municípios da Amazônia/Pará; b) 0 papel do Estado e a lógica das relações de poder no desenvolvimento de suas ações atreladas neste caso, ao desenvolvimento da política urbana. Assim faz-se necessário compreender o paradoxo entre o reconhecimento/não reconhecimento da diversidade urbanoregional e da população dos municípios brasileiros, visto que ao mesmo tempo em que a política prevê a contemplação do direito à cidade e da função social da cidade e da propriedade, a sua efetivação acaba por deixar à margem da cidade, exatamente aqueles sujeitos que têm suas realidades vividas construídas cotidianamente na margem do rio ou da estrada, e que veem essas práticas espaciais diversas e singulares, sendo homogeneizadas no âmbito do planejamento urbano através das representações que se criam desses espaços, mas que por sua vez constituem o espaço do possível, na medida em que são práticas espaciais residuais no/do urbano (LEFEBVRE, 2001).

Palavras-chave: espaço; planejamento urbano; política urbana de habitação; diversidade urbano-regional; Pará.

\section{The housing policy of social interest and the urban dimension in municipalities of the Amazon/ Pará}

ABSTRACT: This text seeks to understand the relationship between the urban policy of social housing in Brazil in its recente period and the urban-regional diversity of the Amazon and in particular on some municipalities in Pará. Accorddingly, we point out how central questions: a) The relationship between urban policy of social housing in Brazil and the urban-regional diversity of the municipalities of the Amazon/Pará; b) The role of the state and the logic of power relations in the development of their shares underlying this case, the development of urban policy. Thus it is necessary to understand the paradox of recognition/non-recognition of the urban-regional diversity and population of municipalities, whereas at the same time that the policy provides for the contemplation of city law and the social function of the city and property, their effectiveness ultimately fail at the margins of the city, just those guys who have lived their daily realities built on the river bank or road, and they see these diverse and unique spatial practices, and homogeneized within the urban planning through representations that these spaces are created, but which in turn constitute the space of possible insofar as they are practical in wastewater spatial/urban (Lefebvre, 2001).

Keywords: space; urban planning; urban housing policy; urban and regional diversity; Pará. 


\section{INTRODUÇÃO}

Tratar do tema da habitação no contexto mais recente da política urbana no Brasil, e neste caso em particular, na Amazônia, leva-nos à compreensão de que for$\mathrm{ma} /$ conteúdo do urbano a que nos referimos, e nesse sentido, também diz respeito aos aspectos que tal política tem tomado como premissa para as intervenções no território.

Esta perspectiva parte da ideia de que para se entender o urbano na Amazônia é necessário, pois, considerar a complexidade do processo de urbanização na região, que ocorreu de maneira diversa e complementar. E desse modo, a política urbana, e nesse caso a política habitacional, deve, em princípio, também, considerar a singularidade desse processo ao pensar as intervenções no e para o espaço regional, a exemplo do desenvolvimento de planos locais de habitação de interesse social, aqui considerados para análise.

Assim, buscamos compreender a relação da política habitacional brasileira, a partir dos princípios e diretrizes do Plano Nacional de Habitação (PlanHab), com a dinâmica urbano-regional da Amazônia, através do desdobramento dessa política na particularidade dos municípios de Oriximiná, São João do Araguaia, São Sebastião da Boa Vista e Vitória do Xingu, respectivamente nas regiões do Baixo Amazonas, Sudeste, Marajó e Sudoeste do Estado do Pará (mapa 1) 1 .

Entrementes, aqui objetivamos tratar da relação que se estabelece entre a política urbana de habitação de interesse social no Brasil, em seu período recente - como dimensão do espaço concebido, e a diversidade urbano-regional da Amazônia e em particular em alguns municípios do Pará - como dimensões do espaço percebido e vivido.

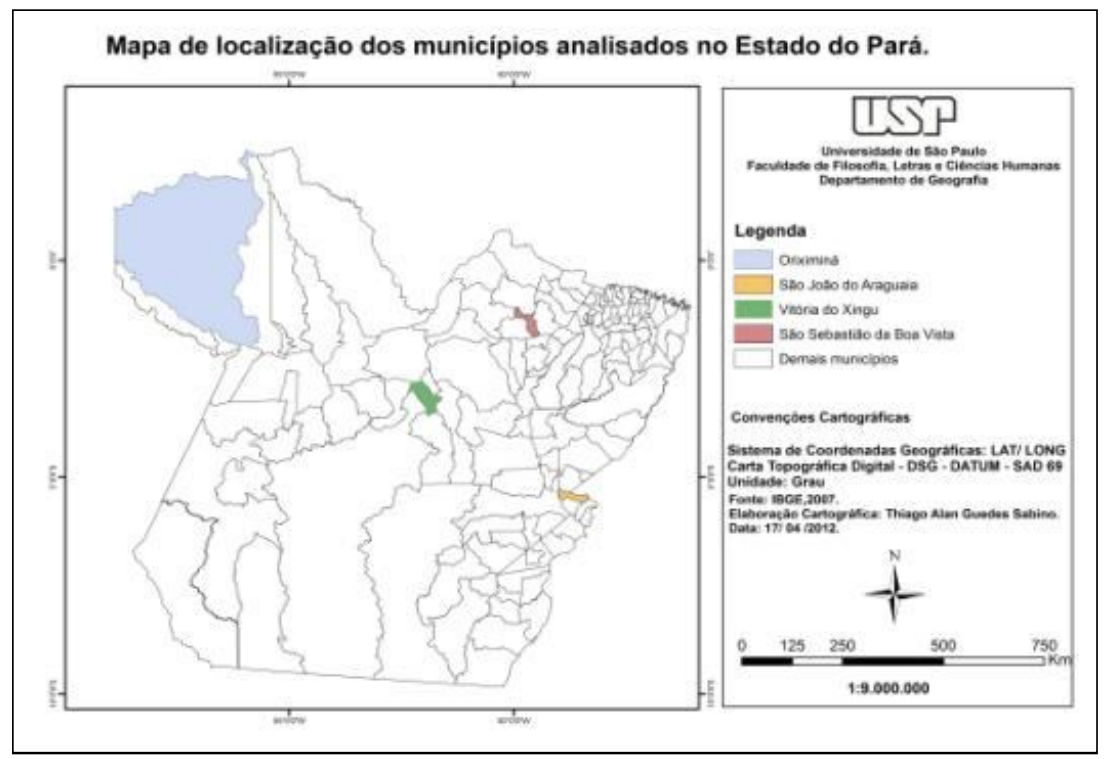

${ }^{1}$ Classificação com base na divisão regional do Instituto Brasileiro de Geografia e Estatística (IBGE) em mesorregiões geográficas. 
Para a análise aqui proposta acerca do entendimento da relação entre o planejamento urbano, partindo do viés da habitação, e a diversidade urbano regional da Amazônia, em sua particularidade do Estado do Pará e de alguns municípios aqui considerados como recorte espacial, lançamos mão da teoria desenvolvida por Henri Lefebvre, denominada de produção do espaço, em que grosso modo, considera as relações sociais e sua relação com o espaço. Diante da problemática delineada para compreensão e análise, a teoria de Lefebvre nos permite estabelecer uma relação entre as relações sociais de produção, o papel do Estado e o espaço, elementos centrais para a discussão proposta acerca do planejamento urbano e a diversidade urbano regional elencada.

Ao tratar da teoria da produção do espaço o autor propõe metodologicamente níveis e dimensões para a compreensão do fenômeno urbano. No primeiro caso, o dos níveis, chama a atenção para "os níveis alcançados pela formação econômica e social", distinguindo então três níveis: o global (concebido), o misto (percebido), e o privado - do habitar (vivido). Nas palavras do autor, o primeiro nível:

No nível global se exerce o poder, o Estado, como vontade e representação. Como vontade: o poder de Estado e os homens que detêm esse poder têm uma estratégia ou estratégias políticas. Como representação: os homens de Estado têm uma concepção política ideologicamente justificada do espaço... Nesse nível entram em ação, com estratégias, lógicas, das quais pode-se dizer, com algumas reservas, que são "lógicas de classe". O poder político dispõe de instrumentos (ideológicos e científicos). Ele tem capacidades de ação, podendo modificar a distribuição dos recursos, dos rendimentos, do "valor" criado pelo trabalho produtivo (ou seja, da mais-valia). Esse nível global é o das relações mais gerais, portanto, as mais abstratas e, no entanto, essenciais: mercado de capitais, política do espaço (LEFEBVRE, 2008, p. 75-76).

O segundo nível, o misto, também denominado mediador ou intermediário, é tratado como "especificamente urbano", sendo definido da seguinte maneira:

Retirou-se, em pensamento, destacando-se do global, o que depende diretamente das instituições e instâncias superiores. 0 que persiste sob o olhar da reflexão conserva uma forma relacionada com o sitio (o meio imediato) e com a situação (o meio distante, condições globais). Esse conjunto especificamente urbano apresenta unidade característica do "real" social, o agrupamento: formas-funções-estruturas. A esse respeito, pode-se falar de duplas funções (na cidade e da cidade: funções urbanas relacionadas ao território circundante e funções internas), assim como de estruturas duplas (por exemplo, as dos "serviços", do comércio, dos transportes; uns a "serviço" da vizinhança: aldeias, burgos, cidades menores e outros a serviço da vida urbana propriamente dita (LEFEBVRE, 2008, p. 77-78). 
Por fim, o terceiro nível, o privado ou do habitar, segundo o autor este é considerado "modesto, senão negligenciável". Cabendo neste caso destacar uma oposição necessária para a compreensão deste nível, entre o habitar e o habitat, tal como ele aponta:

Este último termo designa um "conceito", ou melhor, um pseudoconceito caricatural... Precisamente, o habitat, ideologia e prática, rechaçou ou recalcou o habitar na inconsciência. 0 habitat foi instaurado pelo alto: aplicação de um espaço global homogêneo e quantitativo obrigando o "vivido" a encerrar-se em caixas, gaiolas, ou "máquinas de habitar"... O habitar não deve mais ser estudado como resíduo, como vestígio ou resultado dos níveis ditos "superiores". Deverá, e já pode ser considerado como fonte, como fundamento, como funcionalidade e transfuncionalidade essenciais. Teórica e praticamente, efetuamos uma reinversão de situação, uma inversão de sentido; o que parecia subordinado eleva-se ao primeiro plano... Assim, o próprio movimento dialético e conflituoso, ao mesmo tempo teórico e prático, do habitat e do habitar passa ao primeiro plano" (LEFEBVRE, 2008, p. 78-81).

Neste caso em particular é necessário levar em conta o papel do Estado na produção do espaço, em que, através do planejamento urbano, busca uma homogeneização dos espaços, bem como delineia certas ações voltadas a atender uma determinada "classe social", como ressaltou o autor. E por outro lado, cabe, num movimento de inversão de olhares sobre a dinâmica espacial urbana, revelar o que em princípio apresenta-se ocultado, ou metamorfoseado por representações espaciais, de elementos constitutivos da vida cotidiana, presentes nos espaços de representação das relações materiais e simbólicas do vivido.

\section{A DIVERSIDADE URBANO-REGIONAL NA AMAZÔNIA E A DIMENSÃO DO ESPAÇO VIVIDO}

De acordo com M iranda (2009) cabe ressaltar a importância do papel da nova política de desenvolvimento urbano brasileira, em que é evidenciada a ideia da diversidade territorial, visto que esse é um importante reconhecimento para o delineamento de uma política que leve em conta as particularidades regionais e que, nesse sentido, possa atender em maior grau as demandas dos municípios, buscando assim uma maior aproximação entre as dimensões do concebido (a política habitacional) e do vivido (a diversidade regional, dada pelas particularidades urbanas).

Entretanto, ainda como demonstra a autora, as especificidades regionais, embora tenham sido contempladas no plano da regulamentação, através do Estatuto da Cidade, em termos práticos, ainda têm sido pouco consideradas na efetivação da política urbana e nesse caso em particular, na efetivação da política habitacional, conforme previsto no PlanHab. 
Dessa maneira é que tomamos como referência o desenvolvimento dos Planos Locais de Habitação de Interesse Social dos municípios de Oriximiná, e São João do Araguaia, São Sebastião da Boa Vista e Vitória do Xingu no Pará, para compreendermos o processo de produção de uma diversidade ubano-regional marcada por diferentes práticas espaciais, construídas ao longo da formação socioespacial amazônica.

Nas diferentes realidades urbanas aqui elencadas, o termo diversidade é de fundamental relevância, pois caracterizam não apenas as diferenças das regiões onde se encontram, mas também e fundamentalmente, certo grau de exclusão da política habitacional pensada para a diversidade do território brasileiro. Em primeiro lugar, trata-se de refletir acerca do urbano que é concebido como modelo para o desenvolvimento da política habitacional proposta para o conjunto do território brasileiro; em segundo lugar, queremos chamar a atenção para o fato de que, em certa medida, a diversidade regional, no âmbito dessa mesma política, parece não ter sido levada a cabo na prática da implementação dos programas habitacionais até então desenvolvidos nos municípios brasileiros, e na região amazônica em particular.

Assim, partimos da ideia que, o que tem sido considerado como urbano para o desenvolvimento da política habitacional no Brasil traz como premissa um urbano ideal, imaginário, uma forma concebida que em princípio pode adequar-se a qualquer conteúdo socioespacial no/do território, mas que acaba por desconsiderar um dos princípios base da nova política urbana que é a diversidade regional - e neste caso, por se tratar de uma política urbana - , diversidade urbano-regional ou ainda conforme proposição de Trindade Junior (2010) urbanodiversidade².

Dentre os municípios tomados como referência - Oriximiná, São Sebastião da Boa Vista, São João do Araguaia e Vitória do Xingu- ainda que ambos estejam geograficamente situados em na mesma região - a Amazônia Oriental, eles se desenvolveram a partir de formações socioespaciais diversas e que têm como resultado, dinâmicas socioespaciais específicas.

Tais especificidades delineadas ao longo do tempo por diferentes sujeitos, tempos e espaços constituiu do ponto de vista do processo de urbanização na região diferentes dinâmicas socioespaciais, que trazem a necessidade de fazer uso de uma abordagem relacional para sua compreensão.

\footnotetext{
${ }^{2}$ Ao tratar da urbanodiversidade o autor afirma que: "Trata-se de formas, mas, sobretudo de formações urbanas que revelam diferentes maneiras de expressar o urbano, desde aquelas que categoricamente difundem os valores da sociedade moderna, até mesmo formas híbridas do espaço que denunciam fortes conteúdos rurais entremeados de valores urbanos do passado e do presente... É nesse sentido que a urbanodiversidade aparece como uma premissa de reflexão e de ação na construção de teorias e de agendas urbanas que superem 0 simples pensamento abstrato. Este, mesmo não sendo necessariamente universal, se propõe, algumas vezes, a ser hegemônico. Da mesma forma, a diversidade territorial e urbana, que considere a desigualdade e a diferença, parece se colocar como elemento que estimula ações no âmbito das políticas territoriais e urbanas, no sentido de superar a simples obrigatoriedade do ato de planejar, com base em documentos legais, para se tornar efetivamente um conjunto de ações de gestão pautadas em diagnósticos e diretrizes que sejam permeáveis à realidade socioespacial, a qual, por sua vez, apresenta-se de forma plural e diversa" (TRINDADE JUNIOR, 2010, p. 252-253).
} 
Desta maneira, para entender a dinâmica urbana e os processos socioespaciais dos municípios na região amazônica, e daqueles aqui tomados como referência em especial, é necessário compreendê-los a partir de suas relações com o mundo exterior, seja o seu entorno ou não, mas também, de suas especificidades intraurbanas.

Assim, os processos são, todavia, também desencadeados, pela forma como, na divisão territorial do trabalho, o capital e seus agentes atuam nos espaços regionais, e nesse sentido, é que devemos levar em conta as dinâmicas socioespaciais anteriores a essas ações, ou seja, entender aquilo que Santos (2005) denominou de formações socioespaciais, que nos possibilita de um lado, considerar o espaço como uma dimensão constitutiva do momento histórico e não apenas palco, e por outro, o múltiplo dimensionamento da análise, considerando as escalas geográficas em que os processos e dinâmicas se desenvolvem desigual e combinadamente (SPOSITO, 2004). Dessa maneira, consideramos como as políticas de desenvolvimento territorial - em especial aquelas referentes ao aspecto urbano do território, e aqui voltamos nosso olhar à política urbana de habitação - também se desenvolveram de forma desigual no território, diferenciando seus espaços regionais.

No caso da região amazônica a urbanização também se desenvolveu ao longo dos anos, de forma desigual e combinada, num processo que gerou dois padrões de rede urbana, consideradas suas formações socioespaciais distintas, quais sejam, o padrão dendrítico e o padrão complexo, tal como demonstra Corrêa $(2006)^{3}$.

Desse modo também os municípios por nós delimitados para análise, tiveram suas dinâmicas socioespaciais constituídas e marcadas por diferentes processos ao longo do tempo.

A região do Baixo Amazonas na qual se insere Oriximiná, é fortemente marcada por relações mais próximas com a natureza, e principalmente com o rio, visto que do ponto de vista econômico ainda se desenvolvem atividades voltadas para a extração de madeira, borracha e castanha-do-pará; e a cultura da juta, bem como atividades turísticas, que tem como atrações as praias, cachoeiras, lagos e excursões ecológicas, estas em virtude de a região ser cortada pelo rio Amazonas na confluência com o rio Tapajós e o rio Trombetas, no caso de Oriximiná. A própria circulação nessa região é realizada em sua maioria pela via fluvial (através de barcos de grande, médio e pequeno porte e lanchas que possuem linhas regulares de passageiros e cargas). Na paisagem dessa região, o barco e os pequenos portos são elementos marcantes da diversidade de sujeitos e relações estabelecidas através do rio na margem das cidades.

\footnotetext{
3 "As redes urbanas com formas complexas são aquelas caracterizadas pela existência, na hinterlândia de uma dada cidade regional importante, de diversos padrões locacionais de centros - confluência de rios, contato entre áreas de produção diferentes, localização portuária, junto a minas e fontes termais, em uma ampla, fértil e densamente povoada planície, em torno de um centro industrial antigo, originando, através de mecanismo de economia de aglomeração, uma concentração urbano-industrial etc... A rede dendrítica é a forma espacial mais simples da rede urbana, especialmente nos países de passado colonial. Caracteriza-se pela presença de uma cidade primaz localizada excentricamente à hinterlândia, geralmente junto à embocadura de um rio navegável. Esta cidade antecede geneticamente a ocupação da área à retaguarda e a criação de outros centros da rede, tornando-se a porta de entrada e saída de sua hinterlândia" (CORRÊA, 2006, pp. 38-39).
} 


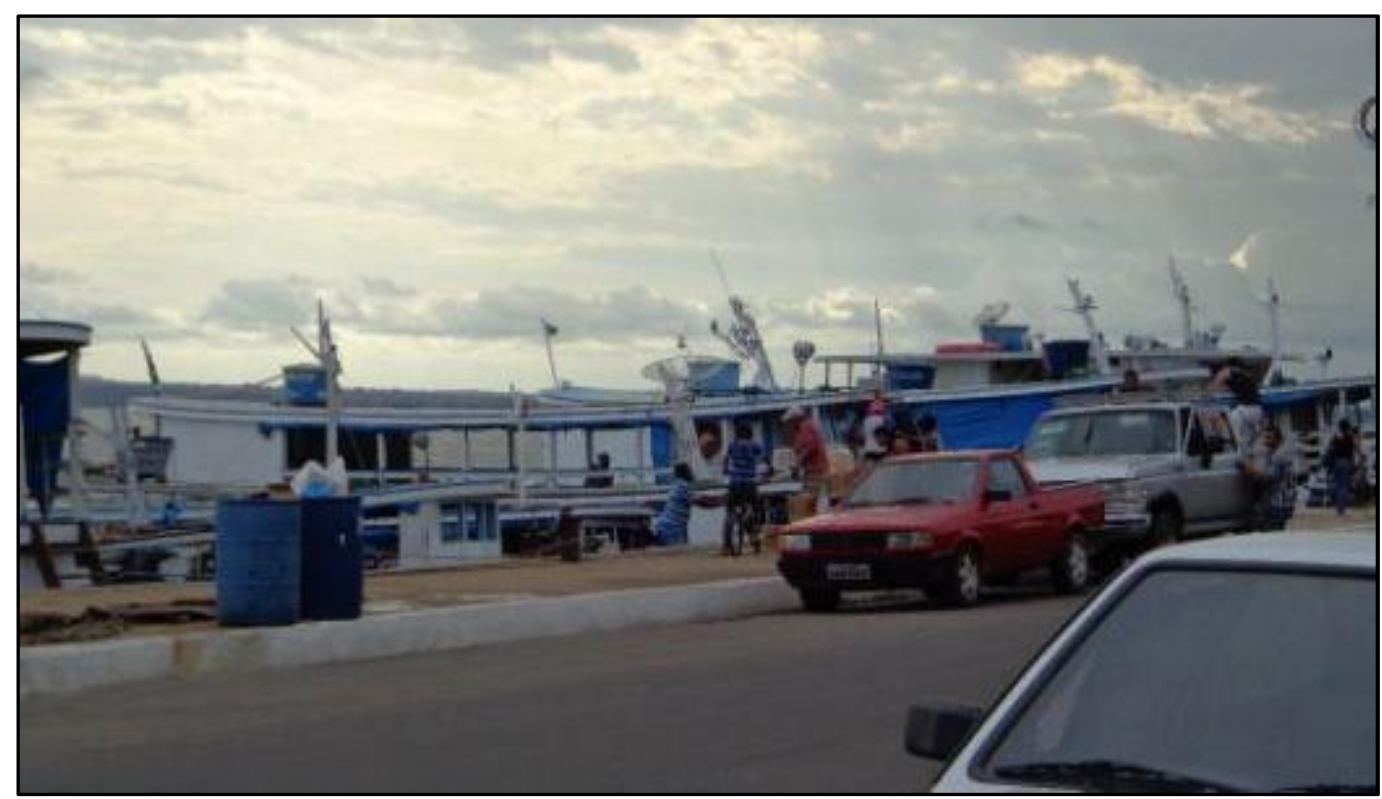

Foto 1: Barcos de transporte de passageiros e cargas no porto de Oriximiná

Fonte: Rovaine Ribeiro, 2013.

Comentário: 0 transporte fluvial é tão presente na paisagem e no cotidiano dessas cidades, que há uma grande diversidade e quantidade de barcos nos pequenos portos. Note-se que todos os barcos têm em seu teto antenas parabólicas e caixas d'água, isso deve-se ao fato do tempo de viagem dessas embarcações para outras cidades, ainda que sejam consideradas "próximas", já que o tempo do barco é como denominou Santos (2002), "o tempo lento".

Além de uma vivência mais associada a elementos tradicionais, especialmente relacionados à cultura ribeirinha, Oriximiná possui uma dinâmica econômica voltada a atividade da mineração (bauxita), explorada pela M ineração Rio do Norte no município. Essa atividade porém se localiza em certa distância da sede municipal, e tem uma dinâmica própria, visto que tem seu próprio núcleo urbano concebido pela empresa (a company town ${ }^{4}$ Porto Trombetas) e que não tem quase nenhuma relação direta com a cidade de Oriximiná, ainda que, em virtude dela outras atividades naquela se concentrem, como serviços de hotelaria, restaurantes, mas principalmente um fluxo mais intenso de pessoas que circula no município, notadamente funcionários da empresa, principalmente pela via fluvial - nesse caso é importante ressaltar que uma das empresa de lanchas - a Viação Tapajós (transporte mais rápido pelo rio) que faz linhas saindo de Santarém para várias cidades da região (Oriximiná, Monte Alegre, Óbidos, Juruti, Alenquer entre outras), tem seu maior fluxo para Oriximiná, tendo apenas para esta cidade mais de uma linha diária, já que para as demais só há um horário de saída ou chegada. Para o caso de Porto Trombetas, há linhas aéreas saídas

\footnotetext{
${ }^{4}$ As company towns, são cidades criadas para atender e assentar os trabalhadores das grandes empresas mineradoras na Amazônia, cidades estas que surgiram no contexto das políticas territoriais do Estado brasileiro através dos Planos Nacionais de Desenvolvimento (PND's I e II) e que no caso da Amazônia estiveram assentados no viés do desenvolvimento econômico com o fomento às atividades de extração madeireira, pecuária e grandes projetos de exploração mineral, a partir das décadas de 1960 e 1970. 0 termo é inicialmente utilizado por Becker 1990, em seus estudos sobre a fronteira na região.
} 
direto de Belém (capital do Estado), ou de cidades médias de importância regional, como Santarém.

Nesse sentido, Oriximiná, têm sua dimensão urbana marcada por duas lógicas de produção do espaço, uma mais associada à vivência cotidiana mais local, de um modo de vida ribeirinho, e outra, mais associada a uma atividade econômica que pouco se integra a esse cotidiano mais particular das vivências.

O segundo município considerado para análise, São Sebastião da Boa Vista, está localizado na mesorregião do Marajó, que possui representações do espaço marcadamente atreladas àquilo que anteriormente apontamos conforme Corrêa (2006), a uma rede urbana dendrítica, em que as relações homem-meio, especialmente ligadas às relações com o rio, fazem parte de seu conteúdo material e simbólico cotidiano.

A região do Marajó, na qual se insere o município de São Sebastião da Boa Vista, ela própria, em seu conjunto de cidades e localidades, têm uma particularidade socioespacial dada por essa forte relação da sociedade com a natureza, visto que o elemento natural tem uma grande influência no modo de vida da população que habita essa região, sendo pois, formada por um conjunto de ilhas, por isso a denominação de arquipélago do Marajó.

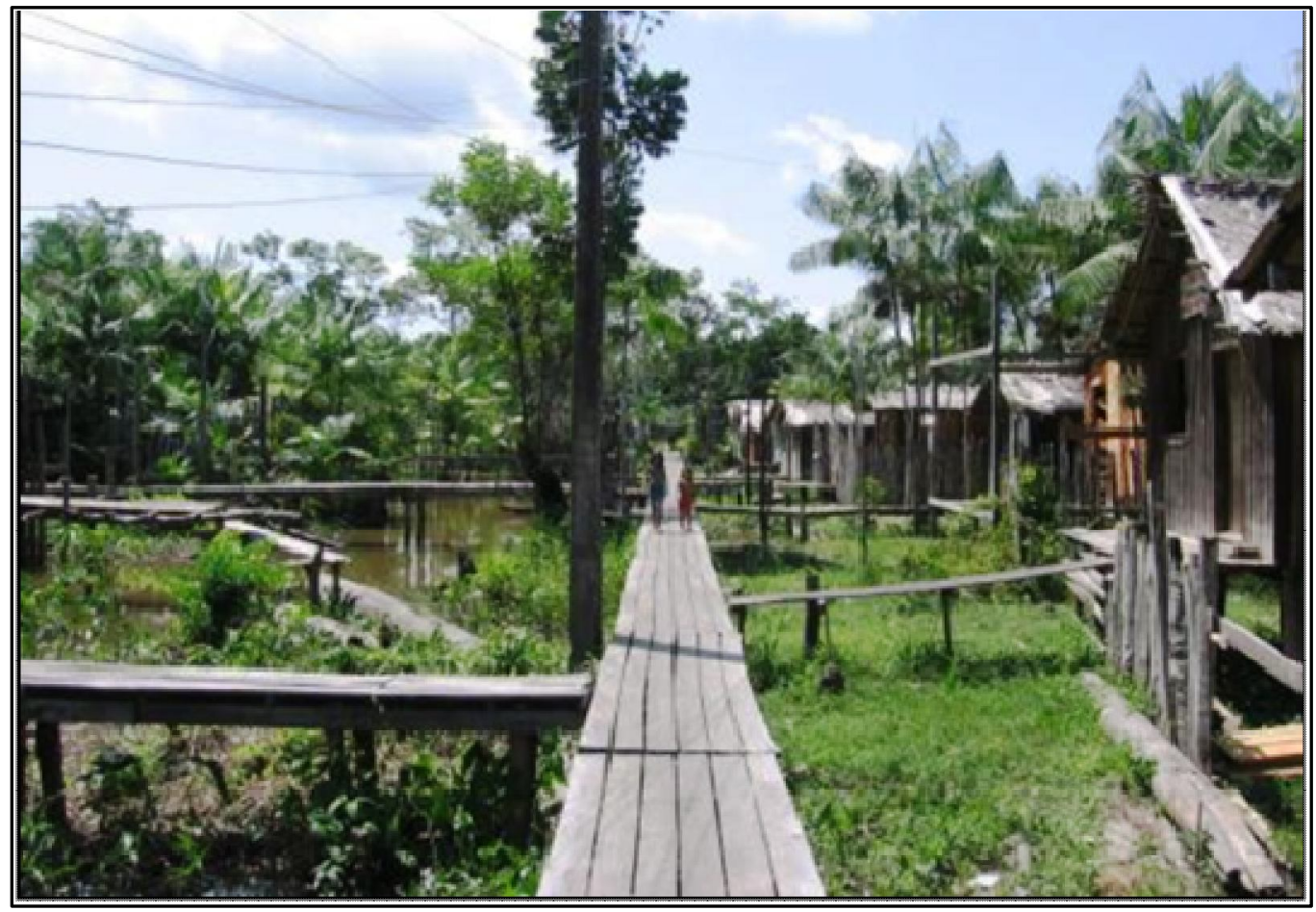

Foto 2: Área urbana do município de São Sebastião da Boa Vista

Fonte: PLHIS - São Sebastião da Boa Vista, 2010.

Comentário: A paisagem da área urbana do município de São Sebastião da Boa Vista demonstra o caráter marcadamente ribeirinho pela presença de estivas - que são ruas feitas de madeira sobre o rio - 0 que reflete a relação de vivência de sua população com este elemento natural, e que representa um modo de vida que se constrói material e simbolicamente no cotidiano deste município. 
Essa dinâmica fortemente associado aos elementos da natureza em São Sebastião da Boa Vista, reflete-se também na organização socioespacial do núcleo urbano, que em grande parte possui casas distribuídas ao longo da margem do rio ou em suas proximidades. Isso relaciona-se ao rio como um elemento central em todo o modo de vida da população local, dado que é por ele que se faz a circulação de pessoas e mercadorias - e neste caso a atividade da pesca, que está voltada para o consumo e também para a comercializaçao em pequena escala. Associado a essa relação mais próxima com a natureza, está ainda a atividade extrativa de frutos da floresta, especialmente 0 açaí - em que a ilha do Marajó é uma das maiores produtoras do Estado. Esse conjunto de elementos que aproximam o homem da natureza nessa região, vai se consituir então nesse chamado "modo de vida ribeirinho", que por outro lado delinea também um conjunto de representações simbólico-materiais particulares na produção do espaço e do conteúdo que dele faz parte. Em que, os hábitos culturais, por exemplo da alimentação (o peixe como parte da alimentação diária associado ao açaí e a farinha),vão influenciar na disposição das moradias na cidade, a proximidade do rio, moradias estas construídas de madeira, geralmente sem forro, dado que, sendo o peixe o principal ítem no cardápio, este ao ser preparado exala um forte cheiro por toda a casa, em virtude disso, além das características já citadas das casas, geralmente elas possuem grandes janelas, permitindo uma maior circulação do ar durante o preparo do alimento, e ainda pelas características climáticas da região, não só do Marajó, mas da Amazônia como um todo, clima quente e úmido. Assim, são práticas cotidianas que se revelam na produção de um espaço, particularmente produzido a partir de uma forte relação do homem com a natureza em todos os seus sentidos, e que marcam mais um elemento diverso do que se convém chamar de urbano na Amazônia.

O terceiro município de referência é o de São João do Araguaia, localizado na região do sudeste do Pará, caracterizada por uma dinâmica socioespacial marcadamente de uma rede urbana complexa, conforme Corrêa (2006), complexidade essa delimitada pelas atividades econômicas voltadas à exploração mineral, à agropecuária e ao extrativismo vegetal (indústrias madeireiras). Essa diversidade econômica é ainda permeada pela diversidade de sujeitos presentes nessa região, especialmente na área rural, já que a terra é um elemento de disputas territoriais, especialmente entre grandes empresas minerais, agropecuárias, movimentos sociais do campo e populações indígenas, e no caso específico do município, também por populações negras.

A região do sudeste paraense, é marcada por relações de conflito entre diversos sujeitos no território, conforme apontado anteriormente. Tais conflitos são oriundos, de uma reestruturação produtiva fruto das políticas territoriais do Estado, principalmente nas décadas de 1960 e 1970, em que o ideário de desenvolvimento regional, mudou a dinâmica socioespacial existente na região - marcadamente por populações indígenas e de núcleos ribeirinhos ao longo dos rios Tocantins e Araguaia. Esse modelo de desenvolvimento, criado a partir da expansão de frentes econômicas para a 
Amazônia, particularmente madeireira, pecuária e mineral, promoveram um intenso fluxo migratório para a região, e de outro lado, acabaram por gerar conflitos pela posse da terra, entre os diversos sujeitos que ali se estabeleceram e os que já habitavam a região, principalmente nas áreas rurais. É daí, também oriunda a organização espacial fortemente marcada pela concentração fundiária, especialmente pelas grandes empresas do setor mineral e agropecuário.

Nesse sentido, as cidades da região, são delineadas por um conteúdo urbano/rural que se estrutura, conforme apontou Malheiro (2012):

Por um processo de desenvolvimento geográfico desigual, que expressa uma forma de geração do valor espacialmente definida na tendência cada vez maior de subordinação dos assentamentos e acampamentos rurais à produção industrial-urbana e do agronegócio, seja pela produção do leite aos laticínios, seja pela produção do bezerro aos frigoríficos, ou pela produção do carvão e do plantio do eucalipto para as siderúrgicas. Porém, territorialmente percebemos que essas relações entre o rural e 0 urbano não se restringem a uma lógica de desigualdade, nesse sentido, o que observamos é o confronto de territorialidades distintas, uma referenciada pela produção mineral e do agronegócio em confronto com territorialidades camponesas, indígenas, de quebradeiras de coco-babaçu, dos atingidos por barragem, dos atingidos por mineração, dentre outros (M ALHEIRO, 2012, p.232233).

A região sudeste expressa bem a materialização da ideia da fronteira, da qual tratou Martins (1997), visto que ainda de acordo com Malheiro (2012):

...entendemos a fronteira como espaço que articula experiências historicamente descontínuas e heterogêneas, seja no âmbito do processo de geração do valor, que, dentre vários outros fatores, inclui trabalho escravo e assalariado, seja no âmbito da produção cultural, que articula múltiplas perspectivas de destino e diferentes experiências espaçotemporais numa dinâmica de passagem, de modo que essas interações são marcadas pelo conflito, como demonstra Martins, também entendido em todas as suas esferas, do conflito ideológico ao conflito agrário e urbano (M ALHEIRO, 2012, p.232233).

Assim, um outro urbano se apresenta, um urbano-rural, delineado pela dinâmica da fronteira que se expressa no conflito pelo uso da terra, e de diferentes sujeitos postos à margem pela intervenção do Estado, seja pelo fomento ao capital agropecuário, seja pelas novas ações que promovem um novo reordenamento do espaço e das espacialidades dos sujeitos nesse espaço.

Por fim, trataremos do município de Vitória do Xingu, sendo uma das mais novas cidades paraenses, localizada na mesorregião do sudoeste do estado do Pará, na porção central do Estado, na margem esquerda do rio Xingu e na margem direita do Igarapé Tucuruí, onde também se localiza a sede do município. 
A formação socioespacial da região em que se insere Vitória do Xingu tem dois grandes momentos, o primeiro, anterior à construção da Transamazônica e à Cuiabá - Santarém, caracterizado por uma estrutura espacial herdada do período colonial e que se expandiu e se consolidou no boom da borracha, até meados da década de sessenta do século XX. É um período iniciado com a conquista e ocupação portuguesa do Vale das Amazonas e de seus afluentes - implantação de fortificações militares e missões religiosas - moldado pela exploração extrativista, alicerçado no sistema de aviamento e tendo como suporte uma rede de núcleos articulados pela circulação fluvial, a rede urbana dendrítica, apontada por Corrêa (2006). Vários núcleos urbanos são remanescentes desse período: Santarém, Juruti, Prainha, Porto de M oz, Itaituba, Aveiro, Altamira, Vitória do Xingu e Senador José Porfírio. O segundo período, é posterior à construção das rodovias Transamazônica e Cuiabá - Santarém (BR-163). É caracterizado pela redefinição da estrutura anterior e que se baseia na agropecuária, na colonização oficial e na interiorização do povoamento por meio de um sistema planejado e misto de ocupação do território - denominado de urbanismo rural - tendo no transporte rodoviário o principal eixo articulador da espacialidade regional, organizando um novo padrão de ocupação espacial, qual seja, a rede urbana complexa (CORRÊA, 2006). 0 processo de colonização do INCRA, baseado na estrutura preexistente de cidades como Altamira, Itaituba e Santarém, induziu o revigoramento e estimulou como centros de polarização do conjunto de novos núcleos urbanos na área de influência da BR-163, planejados e espontâneos, emergentes do Plano Integrado de Colonização (PIC) e dos processos migratórios da região sul e sudeste para as bordas das duas rodovias.

No período atual, o município de Vitória do Xingu, passa, tal como São João do Araguaia, por uma nova fase de reestruturação socioespacial, associada também, a uma nova intervenção do Estado no território, por meio da construção da Usina Hidrelétrica de Belo Monte, que tem no município sua maior área diretamente afetada, do ponto de vista ambiental - mudança do curso do rio pelo barramento - e cultural, já que a maior parte da área alagada é das populações indígenas ${ }^{5}$.

\footnotetext{
${ }^{5} \mathrm{O}$ empreendimento localiza-se na área denominada de Volta Grande do rio Xingu, entre os paralelos 300' e 3040'S e os meridianos 5130' e 52³0'W. Considerando-se o conjunto barragem, reservatório, tomada d'água e casa de força, o empreendimento ocupará terras dos municípios de Vitória do Xingu, Altamira e Brasil Novo. 0 eixo da Barragem Principal situa-se no rio Xingu, cerca de $40 \mathrm{~km}$ a jusante da cidade de Altamira, seguindo-se o encaminhamento pelo rio. 0 Canal de Fuga da Casa de Força Principal localiza-se cerca de 9,5 km a jusante da vila de Belo Monte, que pertence ao município de Vitória do Xingu. 0 principal acesso ao empreendimento se dá através da BR-230 - Rodovia Transamazônica. Há também possibilidade de acesso ao local da usina por via fluvial, desde o porto de Belém, até a vila de Belo Monte supracitada, situada às margens do rio Xingu, que é inteiramente navegável desde sua foz até o local desta vila. Segundo resultados dos Estudos de Viabilidade do CHE (Complexo Hidrelétrico Belo M onte) concluídos pela ELETROBRÁS e ELETRONORTE em 2002, a capacidade instalada do empreendimento corresponderá a 11.181,3 M W, com uma estimativa de energia firme equivalente a 4.719 MW médios anuais na Casa de Força Principal e 77 MW médios na Casa de Força Complementar, a um custo índice de instalação de $\mathrm{R} \$ 748 / \mathrm{kW}$, incluídos os juros durante a construção. 0 empreendimento consta como uma das componentes do Plano de Expansão do Setor Elétrico Brasileiro desde 1986.6365-ElA-G90001b Leme 20 Engenharia Ltda. A energia produzida no aproveitamento em questão visa ao atendimento das 
No que diz respeito a organização socioespacial urbana de Vitória do Xingu, conforme apontado anteriormente, ele tem uma configuração de formas e relações que revelam por um lado, as heranças do passado ribeirinho, da rede urbana dendrítica, visto que ainda se faz grande parte da circulação por via fluvial, e por outro, as marcas de um tempo mais próximo, a dinâmica oriunda das intervenções do Estado na região, pela rodovia e pela migração inter-regional, que demonstram ao mesmo tempo, não apenas formas que se misturam na paisagem, mas também, um conjunto de relações simbólicas, que são principalmente do migrante, e ao mesmo tempo de populações tradicionais, especialmente indígenas. Nesse conjunto diverso de temposespaços e sujeitos que dão conteúdo a eles, delineia-se um outro urbano, que condensa diferentes formas-conteúdos que se materializam no cotidiano desse urbano tão complexo, que se faz marcadamente contraditório, na paisagem e nas práticas espaciais cotidianas.

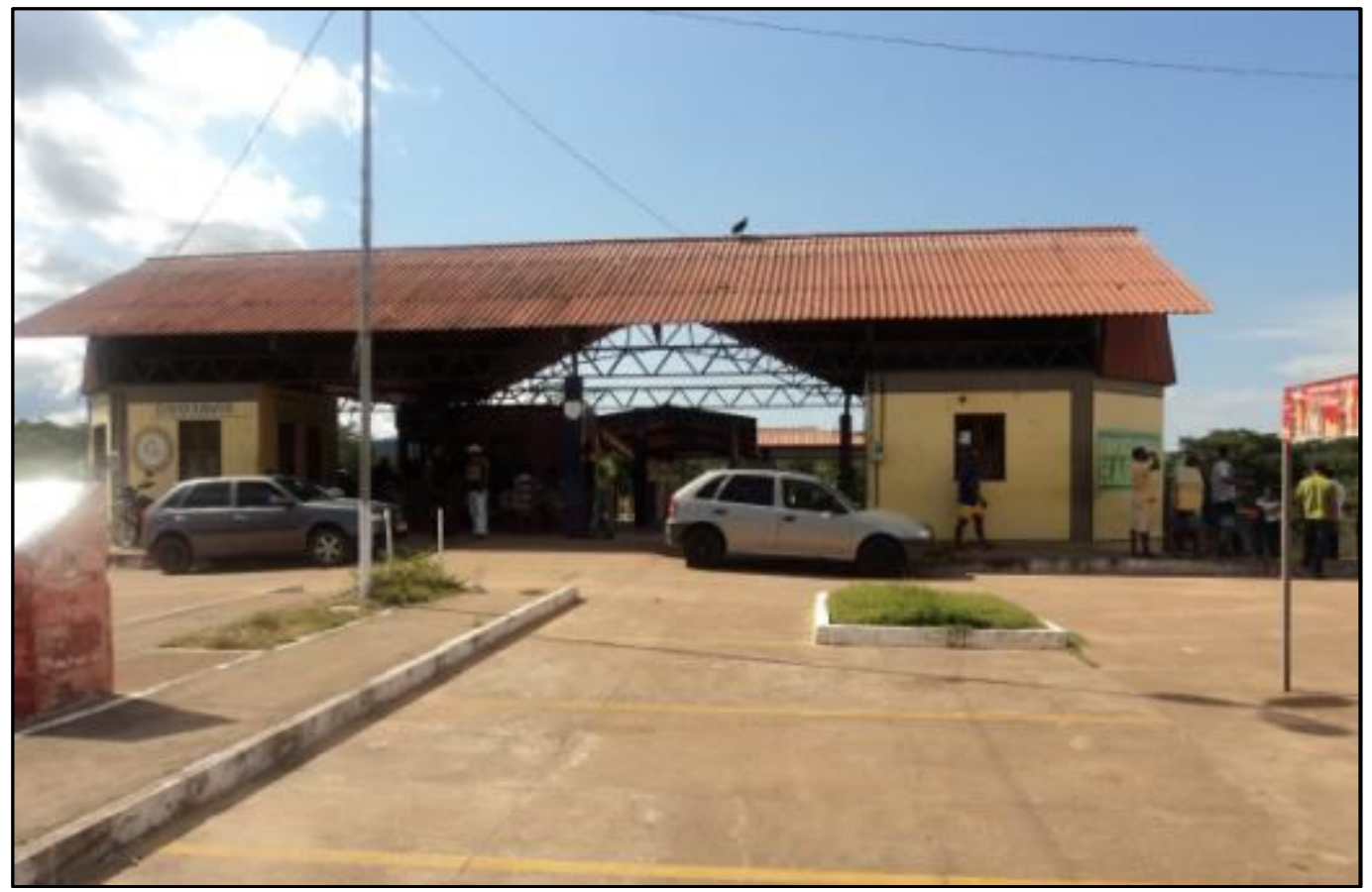

Foto 3: Porto de Vitória do Xingu

Fonte: PLHIS Vitória do Xingu - 2010.

Comentário: 0 porto, demonstra um elemento representativo do padrão de ocupação dendrítico, ainda presente no município, visto que a via fluvial ainda é bastante utilizada no município e na região.

Entrementes, o que se nota, é que em ambos os casos anteriormente elencados, apresentam-se diversidades urbanas em seus vários aspectos, ora com paisagens e

demandas do mercado interno brasileiro, sendo que a usina será interligada ao Sistema Elétrico Nacional (SIN) através de conexão com a Linha de Transmissão (LT) Tucuruí-M acapá-M anaus, ainda a ser implantada e que, em acordo com o Plano Decenal de Expansão de Energia (PDEE) 2007/2016 (M M E/EPE, 2007), tem sua entrada em operação prevista para janeiro de 2012. Esta energia será transportada, além dos centros consumidores do Norte, em sua maior parte para os grandes centros consumidores do Nordeste e Sudeste/Centro-Oeste, que concentram o déficit atual e previsto (EIA/RIM A, Belo M onte, 2006). 
formas-conteúdo, mais associadas a intervenções externas, a espaços concebidos por uma lógica Estado-territorial de modernização do território e da região, ora fortemente marcadas por práticas cotidianas intimamente relacionadas à natureza.

Tais diversidades, têm apontado para a reflexão, no âmbito da produção do espaço, como propôs Lefebvre, do grau de relação entre as diferentes dimensões (concebido, percebido e vivido) no espaço concretamente produzido a partir da problemática habitacional no território brasileiro de modo geral, e na região amazônica em particular, aqui considerada a partir dos municípios paraenses, pelos quais tratamos dessa diversidade urbana, delineada nos diferentes espaços de representação, pelas práticas espaciais dos diversos sujeitos que neles atuam e produzem estes espaços.

\section{A POĹTICA HABITACIONAL E A DIVERSIDADE URBANO-REGIONAL DA AMAZÔNIA}

A discussão da política habitacional na Amazônia nos remete às particularidades da região, a serem incorporadas na política urbana e habitacional pensadas para o território brasileiro em período mais recente, tendo em vista que a política urbana brasileira, nos últimos anos, tem apontado para o reconhecimento do princípio da diversidade urbano-regional do território, conforme Rolnik et al (2011):

Os primeiros anos do século XXI marcaram um novo momento no progressivo movimento de construção de uma institucionalidade para a política urbana no país. Em 2001, foi aprovada no Congresso Nacional a Lei no 10.257, de 10 de julho de 2001, conhecida como Estatuto da Cidade, instituindo as diretrizes e instrumentos de cumprimento da função social da cidade e da propriedade urbana, do direito à cidade e da gestão democrática das cidades. Em 2003, foi criado o Ministério das Cidades, com o horizonte de retomar a agenda de uma política urbana nacional, integrando os setores de habitação, saneamento ambiental e transportes em um mesmo órgão... No mesmo ano foi realizada a I Conferência Nacional das Cidades, que resultou na eleição da primeira composição do Conselho Nacional das Cidades. A primeira Conferência, aprovou, entre os princípios que deveriam orientar a construção da política urbana: 'a promoção do direito à cidade, o desenvolvimento social, econômico e ambiental, o combate à desigualdade social, racial, de gênero e regional; diretrizes e instrumentos que promovam a integração das políticas urbanas por meio das políticas de habitação, saneamento ambiental, transporte e mobilidade, considerando o Estatuto da Cidade e a Constituição; garantia da participação da população e dos vários segmentos da comunidade na formulação, execução e acompanhamento de planos e projetos de desenvolvimento urbano e, diretrizes e orientação que garantem que os investimentos públicos sejam aplicados no enfrentamento das desigualdades sociais e territoriais' (ROLNIK et al, 2011, p. 10-11). (grifos da autora em itálico; grifo nosso em negrito).

Seguindo as diretrizes da política urbana de modo geral, a política habitacional brasileira em seu período mais recente, a partir do Plano Nacional de Habitação (Pla- 
nHab), também traz como princípio a incorporação da ideia do reconhecimento da diversidade regional do território nacional, com vista a atender às demandas socioespaciais dos municípios brasileiros, tal como demonstrado em capítulo anterior.

Neste caso, destacamos em primeiro lugar 'a diversidade regional e dos municípios', que trata daquilo que a nosso ver é fundamental quando se trata da região amazônica e dos municípios aqui tomados como exemplo, que caracterizam realidades complexas e diversas, com dinâmicas socioespaciais diferentes, dentro da mesma região. Em segundo lugar, a necessidade de enfrentar os problemas habitacionais do país de forma diferenciada no que se refere aos processos de produção e financiamento, tendo em vista a diversidade das características sociais e econômicas da população, o que revela outro elemento fundamental para se pensar os municípios aqui elencados, que diz respeito ao caráter do extremo grau de pobreza de grande parte dos municípios da Amazônia, em virtude por um lado, do alto grau de concentração fundiária e de renda, e por outro lado, da expropriação dos recursos naturais e da população local por parte dos grandes agentes econômicos - empresas mínerometalúrgicas, do agronegócio (produção de soja, agropecuária), indústrias madeireiras, atividades de carvoejamento, entre outras - existentes na região. Por fim, destacamos ainda as questões da capacidade institucional, fundiária e urbana regionais, que compõem o conjunto de relações que delineiam uma forma/conteúdo específica, que por sua vez, também tem sido deixada à margem no planejamento urbano, até então proposto através das concepções do espaço urbano por ele propostos.

Nesse âmbito o termo diversidade apresenta-se como eixo norteador na reflexão da política urbana e habitacional na Amazônia, na medida em que nos remete a uma realidade que não é diversa apenas em seu aspecto físico-territorial, mas também no que tange às relações sociais que se criam, se imbricam e se metamorfoseiam na construção de uma dinâmica socioespacial singular na particularidade de seus municípios.

De acordo com M iranda (2009) cabe ressaltar a importância do papel da nova política de desenvolvimento urbano brasileira, em que é evidenciada a ideia da diversidade territorial, visto que esse é um importante reconhecimento para o delineamento de uma política que leve em conta as particularidades regionais e que, nesse sentido, possa atender em maior grau as demandas dos municípios.

Entretanto, ainda como demonstra a autora, as especificidades regionais, embora tenham sido contempladas no plano da regulamentação, através do Estatuto da Cidade, em termos práticos, ainda têm sido pouco consideradas na efetivação da política urbana e nesse caso em particular, na efetivação da política habitacional, conforme previsto no PlanHab.

Assim, ao relacionarmos os elementos propostos no PlanHab com as característica urbanas na região, nos revela que o que tem sido considerado como urbano para 0 desenvolvimento da política habitacional no Brasil traz como premissa um urbano que tem uma forma homogeneizante para o conjunto do território como um todo, e 
que acaba por desconsiderar um dos princípios base dessa mesma política urbana que é a diversidade regional, e nos leva ainda ao desdobramento da questão para a interpretação de que a lógica de reprodução das relações de produção tem deixado marcas no território, através do desenvolvimento de ações estatais no âmbito do planejamento urbano, que tem a muito se revelado contraditórias e complexas.

Considerando alguns dos elementos propostos na política urbana de habitação recente no país, a hipótese que se levantou é a de que no âmbito da política nacional a realidade urbana é pensada a partir de um urbano ideal, que não corresponde, na particularidade dessa análise, à diversidade urbano-regional da região amazônica de modo geral, e dos municípios do Pará em particular, o que em princípio, poderia inviabilizar o desenvolvimento de políticas públicas de habitação que correspondam às reais demandas das populações locais.

Desse ponto de vista o que se observou ao longo da pesquisa é que há um distanciamento entre o plano da concepção do planejamento urbano, que estabelece uma política visando contemplar as demandas regionais e institui regulamentação para legitimar essa concepção, mas que de outro lado, está desatrelada da realidade vivida, em que os recursos e agências de fomento para o financiamento de habitações a exemplo da Caixa Econômica Federal - sejam elas populares ou não, inibem o plano da vivência dos sujeitos, suas práticas materiais e simbólicas, na particularidade do urbano de seus municípios. De maneira que os municípios que tem sua dinâmica socioespacial atrelada ao rio, a características marcadamente ribeirinhas, a exemplo de São Sebastião da Boa Vista e Oriximiná, veem-se obrigados a alterar essa relação para que possam implementar projetos habitacionais em sua área urbana, já que diante dos critérios que determinam o uso de recursos para essa finalidade, a tipologia habitacional ribeirinha é considerada inadequada para moradia.

Ao relacionar-se as concepções do espaço urbano, a partir do que foi proposto pelo Plano Nacional de Habitação, e com reflexo na particularidade dos municípios, aqui tratados especialmente pelo caráter urbano-rural e das relações mais próximas da natureza (o rio e a floresta), especialmente na singularidade da região do Marajó e do município de São Sebastião da Boa Vista.

Ainda nos remetendo às diversidade urbano-regionais dos municípios aqui analisados, nos municípios de São João do Araguaia e Vitória do Xingu, em que o rio não se apresenta como um "problema", pois se trata de municípios com outras características fisiográficas, ainda que, no caso de Vitória do Xingu o rio ainda é um elemento representativo da circulação, ele possui também, como demonstramos no primeiro capítulo, também uma estrutura mais voltada à rede urbana complexa (CORRÊA, 2006) entretanto, o urbano também não é semelhante ao urbano adotado como padrão pelas agências financiadoras, trata-se de uma dinâmica muito mais associada ao rural, conforme descrevemos anteriormente é, nesse sentido, um rural que se imbrica no urbano e que se revela, desse modo, também, diverso. 
Nos quatro municípios analisados, tal como apontado anteriormente, a precariedade da infraestrutura e o elevado grau de pobreza, são critérios pouco significativos para a escolha da parcela da população a ser beneficiada por um determinado programa habitacional a ser desenvolvido no município - tal como indicado pelo M inistério das Cidades para a elaboração dos Planos Locais de Habitação de Interesse Social.

Ainda no que concerne à política habitacional no Estado, e nesse caso, na particularidade dos municípios aqui analisados, ao considerar as potencialidades e limitações dos Planos Locais, especialmente naqueles pertencentes à região sudeste do estado, M alheiro $(2012)^{6}$ destaca o seguinte quanto às potencialidades:

A exigência da participação popular para a legitimação dos produtos do PLHIS desenha uma primeira potencialidade do plano, de construir um ambiente de decisão participativa em lugares nos quais, historicamente, as decisões são concentradas e onde se têm, devido a uma trajetória de patrimonialismo político, em que dificilmente se distinguem os limites do público e do privado, uma diminuta cultura participativa no âmbito das administrações municipais.

Este aspecto reforça a importância e potência de determinados atores sociais na definição de uma política mais democrática e ressalta, primeiramente, a centralidade e alto grau de participação dos movimentos de luta pela Reforma Agrária...Porém, os movimentos e ativismos sociais urbanos ainda não assumiram um papel de protagonistas na cena política das decisões nos municípios, talvez porque, vale lembrar, ainda são poucos os movimentos organizados ligados à questão urbana.

Um segundo ponto importante do PLHIS é que ele reacende a discussão em torno de instrumentos da política urbana e agrária e cria bases para a consolidação de uma política sistemática de habitação de interesse social, a partir principalmente da criação do Fundo M unicipal de Habitação de Interesse Social (FM HIS) e do Conselho M unicipal de Habitação.

Um terceiro aspecto a ressaltar é o exercício do planejamento e a definição de ações concretas para o enfrentamento da questão habitacional desenhadas a partir das especificidades locais e particularidades regionais, como aconteceu com os municípios aqui ressaltados (MALHEIRO, 2012, p.240-241).

Dentre as limitações elencadas por Malheiro, na experiência dos Planos Locais no sudeste paraense, destacam-se, segundo 0 autor:

\footnotetext{
${ }^{6}$ Bruno Cézar Pereira Malheiro, técnico da Ação PLHIS/Pará, foi um dos coordenadores das equipes de apoio nos Polos onde os planos foram desenvolvidos. Coordenou a equipe do Polo M arabá, que compunha os municípios de Curionópolis, Eldorado dos Carajás, Pau D'Arco, São João do Araguaia e Sapucaia. As informações aqui destacas, são fruto das discussões e relatos de experiências dos técnicos do projeto, que ao final do processo deram origem a uma coletânea de artigos no livro "A questão da habitação em municípios periurbanos na Amazônia".
} 
Entretanto, apesar das potencialidades, várias limitações são evidentes. A primeira delas é o certo desprestígio dado pela própria estrutura da Política Nacional de Habitação de Interesse Social, principalmente porque estes planos não são pré-requisito de grandes programas, como o Minha Casa Minha Vida. Embora o plano seja condição de acesso aos recursos do Fundo Nacional de Habitação de Interesse Social e para o acesso a editais, ainda assim, tem sua importância reduzida para membros da administração municipal e mesmo da sociedade em geral.

Algumas limitações são resultantes da própria particularidade regional, como a limitada capacidade de participação da população na elaboração e execução da política habitacional, devido ao patrimonialismo inscrito nas formas de exercício do poder das prefeituras. Além disso, visualizamos que o planejamento é tratado pelas prefeituras dos cinco municípios em foco, como um ônus político, em virtude de se privilegiar ações de curtíssimo prazo, desprestigiando o PLHIS, ou seja, a projeção de cenários e a definição de estratégias de médio e longo prazo parecem não render um bônus eleitoral imediato e, por isso, tais ações acabam ficando em segundo plano. Houve também extrema dificuldade na coleta de dados pelo próprio município, uma vez que dificilmente esses dados estavam atualizados (M ALHEIRO, 2012, p.241).

Diante do quadro de avanços e limitações ora apresentados, no Estado e nos municípios tomados como referência empírica, cabe ainda ressaltar que, dentre os quatro, verificou-se que, ainda que tenham sido partícipes de um conjunto de ações que visavam fomentar a política de habitação de interesse social - as orientações técnicas, o levantamento de informações e formação de um banco de dados sobre as necessidades habitacionais, a capacitação de técnicos, o fortalecimento institucional, a adesão a SNHIS, a criação do FMHIS e do Conselho Gestor do Fundo, e mais importante, a participação popular e a democratização das decisões, nenhum dos municípios aqui elencados, teve uma política efetivada após a finalização de todo esse processo $^{7}$.

Dessa maneira, chama a atenção que a não efetivação da política habitacional desses municípios, pode dever-se por um lado, pelo fato de que as propostas calcadas pela participação popular, que objetivavam incorporar a diversidade urbano-regional em seus planos locais, acabaram se esbarrando no plano do concebido, pelas gestões municipais subsequentes, que abandonaram ou deixaram de lado todo um esforço

\footnotetext{
${ }^{7}$ É importante ressaltar que não conseguimos entrevistar todos os sujeitos identificados como responsáveis pela elaboração da política em âmbito municipal, em virtude do não acesso aos mesmos, dado que a maioria envolvida no processo naquele momento, eram sujeitos "temporários", e que ao final da gestão, como ocorre na maioria dos municípios do Estado, "saíram" por assim dizer, dos papéis que lhe eram atribuídos na elaboração dos planos locais. Outra observação importante a ser destacada é que, no caso dos sujeitos das secretarias ou órgãos que seriam responsáveis pela implementação da política habitacional na gestão atual, não tinham informações ou não sabiam da existência do Plano. Municipal de Habitação, à exceção apenas do município de Oriximiná , em que a entrevista realizada com uma das técnicas que foi responsável pela elaboração do Plano, sabia do que se tratava, mas também não houve a implementação do plano proposto até o momento da realização da entrevista em agosto de 2013.
} 
político social sobre as demandas habitacionais locais. Esse "engavetamento" dos PLHIS, deve-se ainda pela incorporação do MCMV como centralidade na produção habitacional nos municípios, reforçando o caráter imediatista da gestão, conforme já apontou M alheiro (2012).

Nesse sentido, pensar a diversidade regional é fundamental não apenas para a compreensão da diversidade dos municípios brasileiros, mas também, e principalmente, refletir sobre o papel de uma política urbana e nesse caso habitacional, que permita a aproximação entre o plano da concepção do planejamento urbano e a realidade vivida dos sujeitos que materializam essa concepção na sua realidade cotidiana, e sem a qual pensar um plano local de habitação seria no mínimo comprometedor no desenvolvimento de uma política urbana e habitacional nesses municípios, na medida em que as particularidades urbanas e regionais são também elemento delineador da diversidade socioespacial do urbano brasileiro.

Assim faz-se necessário compreender o paradoxo entre o reconhecimento/não reconhecimento da diversidade urbano-regional e da população dos municípios brasileiros, visto que ao mesmo tempo em que a política prevê a contemplação do direito à cidade e da função social da cidade e da propriedade, a sua efetivação acaba por deixar à margem da cidade, exatamente aqueles sujeitos que têm suas realidades vividas construídas cotidianamente na margem do rio ou da estrada, e que vêem essas dinâmicas socioespaciais diversas e singulares, sendo homogeneizadas no âmbito do planejamento urbano através das representações que se criam desses espaços (LEFEBVRE, 2001).

\section{ALGUMAS CONSIDERAÇÕES}

A partir dessa breve reflexão, consideramos que a problemática chave da questão, não está apenas na elaboração dos princípios e diretrizes da política, ao considerar um tipo de urbano para a grande diversidade do território nacional refletida nesse caso em seus municípios, mas para, além disso, o que apontamos como fundamental é o distanciamento entre a política e a implementação dos programas habitacionais que impõem aos municípios um padrão urbano que tende a reordenar o espaço, e que acabam por desconsiderar essa mesma diversidade regional/territorial/social, que se estabelece como um dos princípios base dessa política.

0 que se revela nessa análise é que, para que compreender o espaço urbano enquanto campo de possibilidades, pelas práticas espaciais que nele se materializam através dos diversos sujeitos que dele se apropriam e nele se reproduzem, à maneira como propôs Souza (2010, 2011), e Lefebvre, no caso do espaço urbano da Amazônia, e dos municípios de Oriximiná, São João do Araguaia, São Sebastião da Boa Vista e Vitória do Xingu, alguns elementos fundamentais devem ser considerados: a) A particularidade regional de estruturas arcaicas que persistem, como campo cego na relação da questão habitacional e das práticas espaciais de diferentes territorialidades na 
cidade; b) A diversidade urbano-regional apresentada apenas na concepção dos Planos, mas escamoteada na ação concreta da produção habitacional pela via da apropriação privada fomentada pelo Estado, em detrimento da luta social pela reforma urbana e 0 direito à cidade como uso nos/pelos espaços de representação material e simbolicamente concretos.

Desse modo, o que se tem na prática, é o contrassenso entre o reconhecimento/não reconhecimento da diversidade socioespacial e da população dos municípios brasileiros, visto que ao mesmo tempo em que a política habitacional de interesse social, prevê a contemplação do direito à cidade e da função social da cidade e da propriedade, a sua efetivação acaba por deixar à margem da cidade, exatamente aqueles sujeitos que têm suas realidades vividas construídas cotidianamente na margem do rio ou da estrada, e que veem essas dinâmicas socioespaciais diversas e singulares, sendo homogeneizadas no âmbito do planejamento urbano através das representações que se criam no espaço urbano no qual se inserem, e que desconsideram as relações simbólico-materiais dos sujeitos que neles estão presentes (LEFEBVRE, 2001).

\section{REFERÊNCIAS}

BECKER, Berta K. Fronteira e urbanização repensadas. In: BECKER, B; MIRANDA, M. M ACHADO, L. O. (Orgs.) Fronteira amazônica: questões sobre a gestão do território. Brasília: Editora da Universidade de Brasília; Rio de Janeiro: Editora da Universidade Federal do Rio de Janeiro, 1990. (pp. 131-144)

CORREAA, Roberto Lobato. Estudos sobre a rede urbana. Rio de Janeiro: Bertrand Brasil, 2006.

LEFEBVRE, Henri. 0 direito à cidade. São Paulo: Centauro, 2001.

3a reimpressão. 2008.

A revolução urbana. Trad. Sérgio Martins. Belo Horizonte: Ed. UFM G, 1999. MALHEIRO, Bruno Cézar Pereira. Diversidade territorial e questão habitacional na fronteira: a experiência de elaboração dos planos locais de habitação de interesse social no sudeste do Pará. In: SANTANA, J. V.; HOLANDA, A. C. G; M OURA, A. do S. F. de. (Orgs.). A questão da habitação em municípios periurbanos na Amazônia. Belém: Ed. UFPA, 2012. Pp. 231-246.

M IRANDA, Lívia I. B. de. A reforma urbana, as políticas territoriais e a questão urbanarural: uma integração necessária. In: BITOUN, J.; MIRANDA, L. (Orgs.) Desenvolvimento e cidades no Brasil: contribuições para o debate sobre as políticas territoriais. Recife: FASE: Observatório das Metrópoles, 2009. pp. 151-173.

ORIXIM INÁ. Plano Local de Habitação de Interesse Social - Etapa do Diagnóstico Habitacional. 2010.

ROLNIK, Raquel; CYM BALISTA, R.; NAKANO, Kazuo. Solo urbano e habitação de interesse social: a questão fundiária na política habitacional e urbana do país. In: 
http://www.usp.br/srhousing/rr/docs/solo_urbano_e_habitacao_de_interesse_social .pdf (acessado em 03 de janeiro de 2011).

SANTANA, Joana Valente; HOLANDA, Anna Carolina Gomes; M OURA, Aldebaran do Socorro Farias de. (Orgs.). A questão da habitação em municípios periurbanos na Amazônia. Belém: Ed. UFPA, 2012.

SANTOS, Milton. A natureza do espaço: técnica e tempo, razão e emoção. São Paulo: Edusp, 2002. (Coleção Milton Santos; 1 )

. Da totalidade ao lugar. São Paulo: Edusp, 2005. (Coleção Milton Santos; 6) SÃ̃ JOÃO DO ARAGUAIA. Plano Local de Habitação de Interesse Social - Etapa do Diagnóstico Habitacional. 2010.

SÃO SEBASTIÃO DA BOA VISTA. Plano Local de Habitação de Interesse Social - Etapa do Diagnóstico Habitacional. 2010.

SOUZA, Marcelo Lopes de. Habitação: eu planejo, tu planejas... NÓS planejamos. Revista Eletrônica de Jornalismo Científico. Campinas, n. 88, jun. 2007. Disponível em: বttp:// comciencia.br/comciencia/handler. php?section $=8 \&$ edicao $=25 \& i d=278>$. Acesso em: 10 jul. 2011.

. Com o Estado, apesar do Estado, contra o Estado: os movimentos urbanos e suas práticas espaciais, entre a luta institucional e a ação direta. Revista Cidades. Vol. 7, no 11. 2010. pp. 13-47.

. Mudar a cidade: uma introdução crítica ao planejamento e à gestão urbanos. 8a ed. Rio de Janeiro: Bertrand Brasil, 2011.

SPOSITO, Maria Encarnação Beltrão. 0 chão em pedaços: urbanização, economia e cidades no Estado de São Paulo. Presidente Prudente: [s.n.], 2004. (Tese de Livre Docência)

TRINDADE JR., Saint Clair Cordeiro da. Diferenciação territorial e urbanodiversidade: elementos para pensar uma agenda urbana em nível nacional. Revista Cidades. Vol. 7, no 12. 2010. pp. 227-255.

Cidades na floresta: os "grandes objetos" como expressões do meio técnicocientífico informacional no espaço amazônico. Revista do IEB. n51. 2010 mar./ set. p. 113-137.

VITÓRIA DO XINGU. Plano Local de Habitação de Interesse Social - Etapa do Diagnóstico Habitacional. 2010.

\tttp://siscom.ibama.gov.br/licenciamento_ambiental/UHE\%20PCH/Belo\%20M onte /Volume\%2001\%20-\%20Caracteriza\%C3\%A7\%C3\%A30\%20do\%20Empreendimento/ TEXTO/EIA\%20-\%20Cap\%C3\%ADtulo\%201,2,3\%20e\%204.pdf>. (Acesso em: 29 jul. 2010)

Artigo recebido em 14 de julho de 2016.

Aprovado em 18 de julho de 2016. 